\title{
Experimental determination of electromagnetic brake parameters of the positioning system
}

\author{
Piotr Perz ${ }^{1}$, Dominik Wilczyński ${ }^{1, *}$, Ireneusz Malujda ${ }^{1}$ \\ ${ }^{1}$ Poznan University of Technology, Chair of Basics of Machine Design, Piotrowo Str. 3, Poland
}

\begin{abstract}
The paper presents the results of an electromagnetic brake test of a hybrid positioning system consisting of a pneumatic cylinder and an electromagnetic brake. Brake tests were carried out on the MTS Insight testing machine, which determined the attraction forces of the electromagnet depending on the size of the air gap and the current flowing through the winding of the electromagnet. The time constants of the positioning unit and the electromagnet were measured, which allowed to develop an effective control system reaching shorter times and higher positioning accuracy as well as a higher average piston speed. The presented system ensures free programming of displacements of the actuator and maintaining the set position. Obtaining higher average speeds of the pneumatic cylinder piston is possible due to the use of effective control parameters such as shortening the braking phase and the time of reaching the desired position.
\end{abstract}

Keywords: pneumatic drive, positioning system, control, electromagnetic brake

\section{Introduction}

The paper presents the construction of a hybrid positioning system consisting of a dual action piston-rod actuator and an electromagnetic brake. The positioning unit operates differently in comparison to known control methods used with positioning equipment. The proposed hybrid positioning system allows to maintain the desired position, achieve shorter positioning time, higher average piston speed and positioning accuracy. Maintaining these parameters required analyzing the dynamics of the electromagnetic brake and the pneumatic positioning system. To quote the subject literature: "The problem with positioning accuracy of pneumatic servo operators stems from the complex, non-linear conversion process of compressed air energy to mechanical energy of the piston-rod motion. Finding the solution to this problem is difficult to achieve do to the insufficient and incomplete knowledge in this regard, but is of particular importance in controlling the positioning of pneumatic servo operators" [1].

The electropneumatic servo mechanisms are characterized by unstable operation, are susceptible to external and internal interferences [2]. The issues with positioning inaccuracy

\footnotetext{
* Corresponding author: dominik.wilczynski@put.poznan.p1

Reviewers: Marian Dudziak, Radosław Pytliński
} 
and the elimination of interferences are solved by utilizing regulators and feedback loops for non-measurable state variables [3]. The study of the electromagnetic brake on the strength testing machine and measuring time constants of the positioning system allowed to design an effective control system. The necessary condition for selecting the optimal mode and controller settings is the possession of information regarding the dynamic properties of the controlled object. The source of the signal determining the control functions is the string potentiometer for registering displacement which allows to control the non-measurable state variables of the piston: velocity and acceleration by differentiating and integrating the control signal.

\section{Determining the parameters of the electromagnetic brake of the positioning system}

For the study of the positioning system, the software LabVIEW by National Instruments together with the data acquisition card National Instruments NI PCI-6221 were utilized. The controller cards, one of which being the state variable regulator, the other being a PID regulator, were simulated digitally in the LabVIEW software environment. Figure 1 shows the data acquisition card as a peripheral. In reality, the card is located inside the computer, connected via PCI interface.

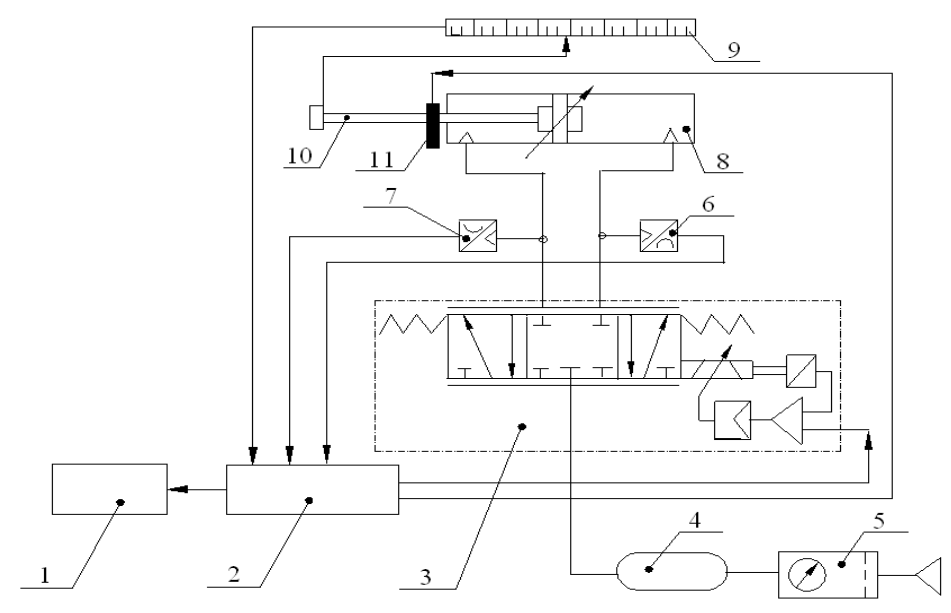

Fig. 1. Block diagram of the testing station of the positioning system with electromagnetic brake: 1 - PC, 2 - data acquisition card, 3 - proportional valve, 4 - vessel, 5 - air preconditioning system, 6,7 - pressure sensor, 8 - dual action piston-rod actuator, 9 - string potentiometer, 10 - piston rod, 11 - brake system with electromagnet [4]

Figure 2 shows the block diagram of the NI PCI-6221 data acquisition card functions. 


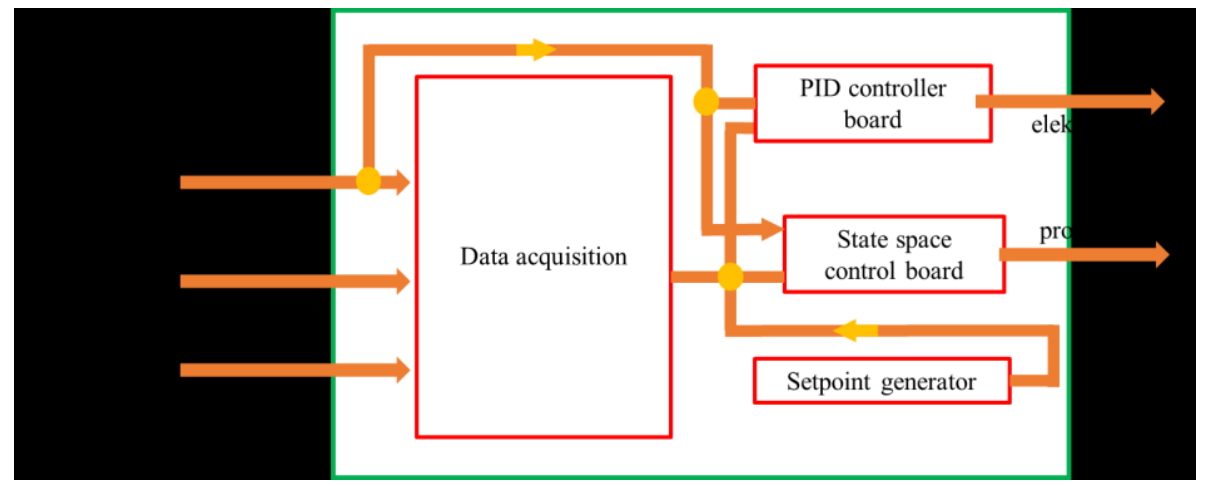

Fig. 2. Block diagram of NI PCI-6221 data acquisition card functions [4]

Figure 3 shows the construction of the positioning unit with electromagnetic brake.

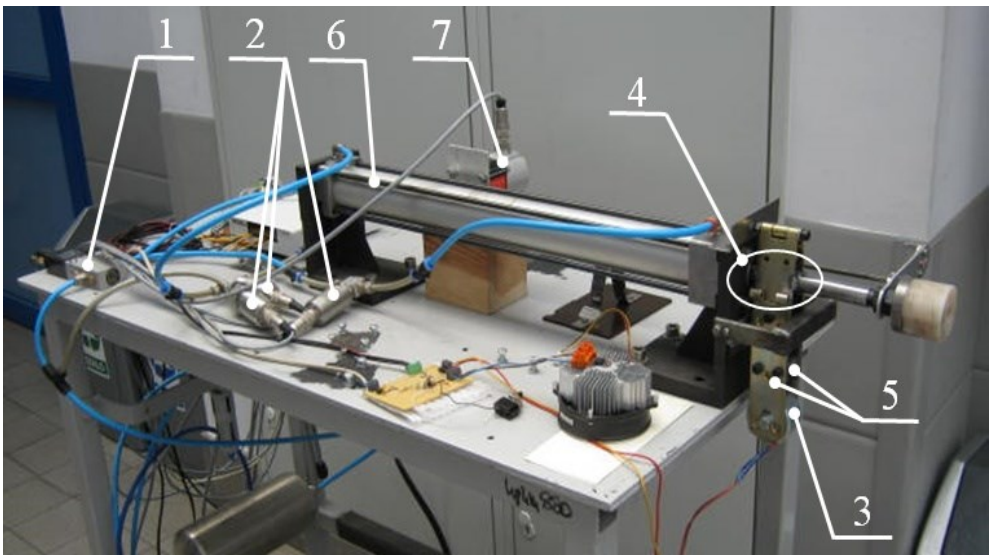

Fig. 3. Positioning system with electromagnetic brake: 1 - proportional valve, 2 - pressure sensor, 3 - electromagnet, 4 - brake linings, 5 - brake arms, 6 - dual action piston-rod actuator, 7 - string potentiometer [4]

Figure 4 presents the operating principle of the positioning system brake. 


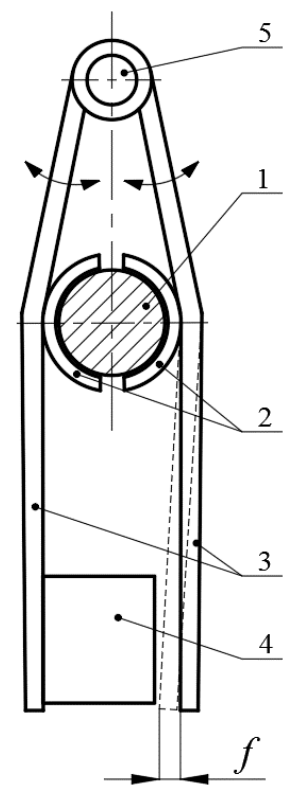

Fig. 4. Positioning system brake 1 - piston rod, 2 - brake linings, 3 - brake arms, 4 - electromagnet, 5 -brake arms axis of rotation, $f$ - brake arms deflection value [5]

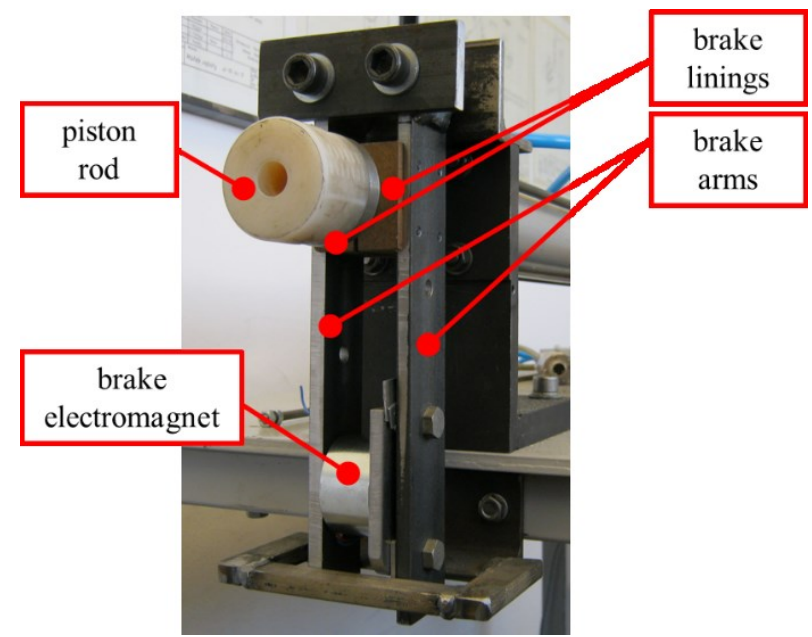

Fig. 5. Positioning system brake

The study of the brake was carried out using a strength testing machine MTS Insight, allowing to determine the attraction force of the electromagnet depending of the dimensions of the air gap and the intensity of current in the electromagnet coils. Measurements were performed for the time constants of the positioning unit and the electromagnet which allowed to devise an effective control system. The acquisition of data and control signal for the pneumatic actuator was performed with NI PCI-6221 data acquisition card. The electromagnet control unit consists of positioning transducer acting as the measuring system acquiring the current position of the piston rod of the actuator and PID regulator coordinating the position deviation. The generator acting as the source of set parameters is simulated by software and the rectangular signal is sent from the data acquisition card. The brake system utilizes an electromagnet type ITS-PE5029-24VDC with rated power $39 \mathrm{~W}$ 
and holding force $500 \mathrm{~N}$. By reducing the brake arms (Fig. 4) to the case of beam deflection as on Figure 6, the deflection value $f[6-8]$ (Fig. 6) could be determined. Subsequently, the time constant for the positioning value was measured.

The deflection value was calculated from the following formula:

$$
f=\frac{F \cdot a^{2} \cdot(l+a)}{3 E J},
$$

where:

$$
f=1.22 \mathrm{~mm}
$$

$$
\begin{aligned}
& F=500 \mathrm{~N} \\
& l=56 \mathrm{~mm} \\
& a=138 \mathrm{~mm} \\
& J=2400 \mathrm{~mm}^{4} \\
& E=2.1 \cdot 10^{5} \mathrm{MPa}
\end{aligned}
$$

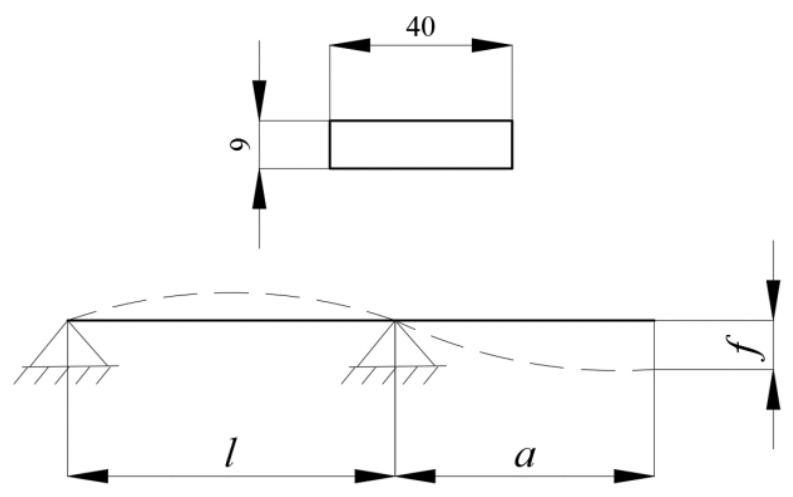

Fig. 6. Beam deflection value

Despite using the beam (brake arms) with thickness $9 \mathrm{~mm}$ and width $40 \mathrm{~mm}$, deflection does occur achieving the value equal to $1.22 \mathrm{~mm}$. This causes an air gap between the electromagnet and the brake arm. This has a significant effect on the electromagnet's attraction force, which determines the system dynamics. The drawings below show the characteristics of the change in attraction force as a function of the gap dimensions for different values of current intensity powering the electromagnet. 


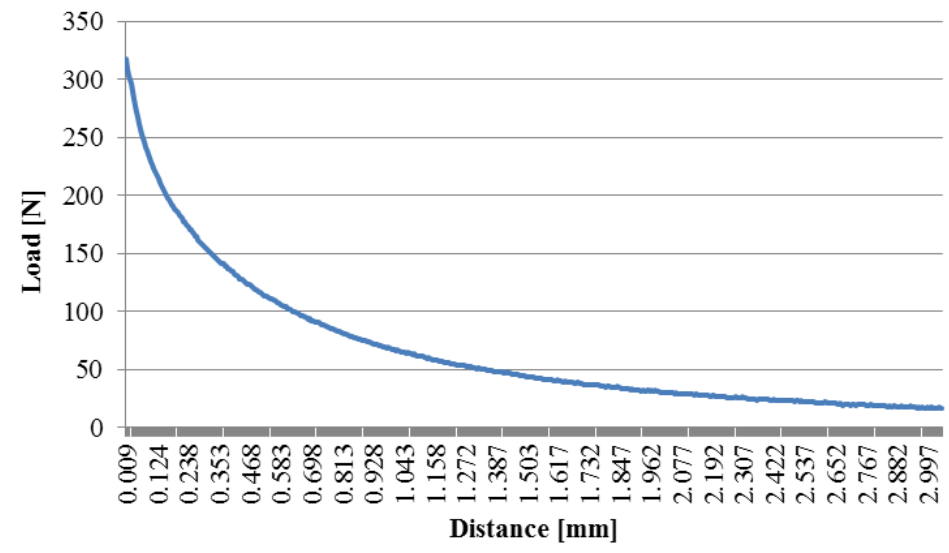

Fig. 7. Characteristics of change of the electromagnet attraction force as a function of the gap width and the intensity of the supplied current equal to $0 \mathrm{~A}$

The electromagnet exhibits the largest holding force value at zero current and zero air gap distance (Fig. 7), these parameters allow to obtain the highest dynamics of the positioning system.

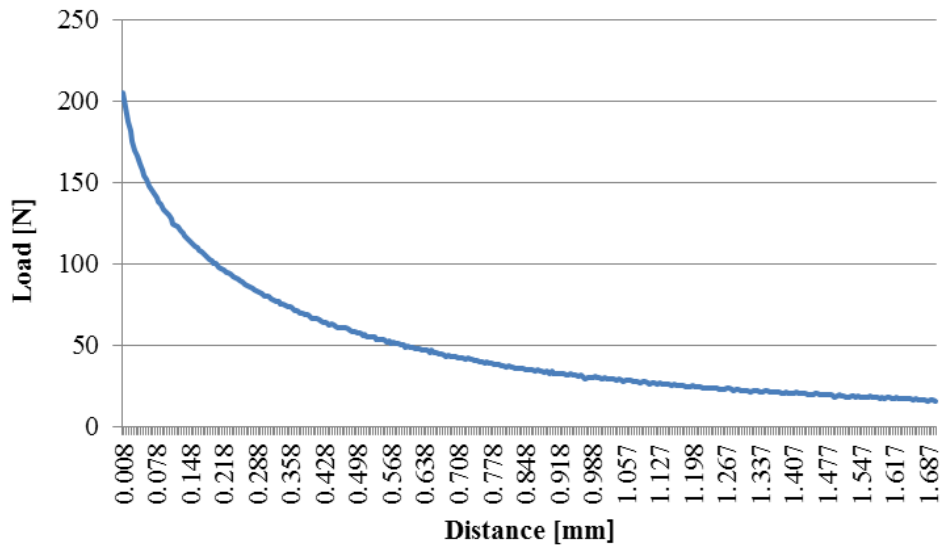

Fig. 8. Characteristics of change of the electromagnet attraction force as a function of the gap width and the intensity of the supplied current equal to $0.5 \mathrm{~A}$

Together with the increase of current intensity in the electromagnet coil, the holding force value decreases to $200 \mathrm{~N}$ at zero air gap distance. The higher the air gap distance, the smaller the holding force (Fig. 8). 


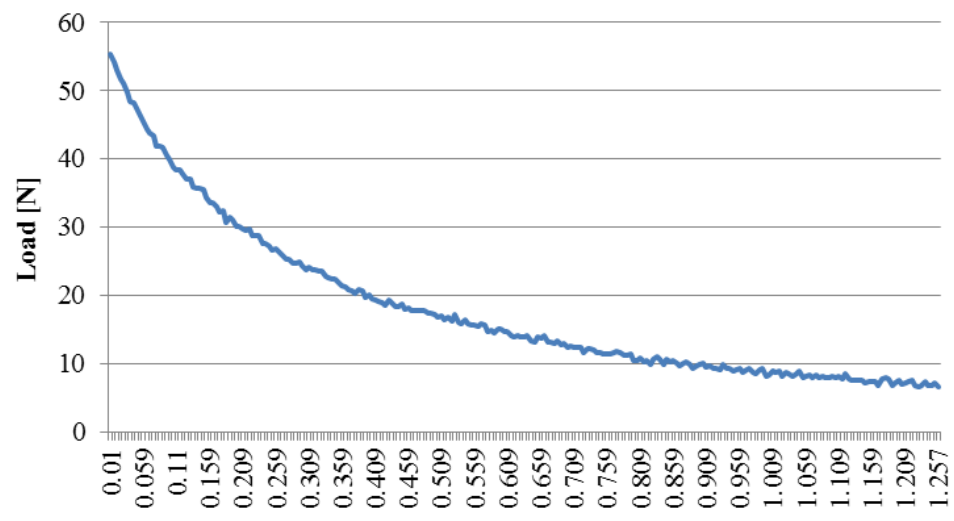

Distance [mm]

Fig. 9. Characteristics of change of the electromagnet attraction force as a function of the gap width and the intensity of the supplied current equal to $1 \mathrm{~A}$

With further increase in the current intensity to $1 \mathrm{~A}$, the force decreases to $55 \mathrm{~N}$ and decreases further as the air gap distance increases.

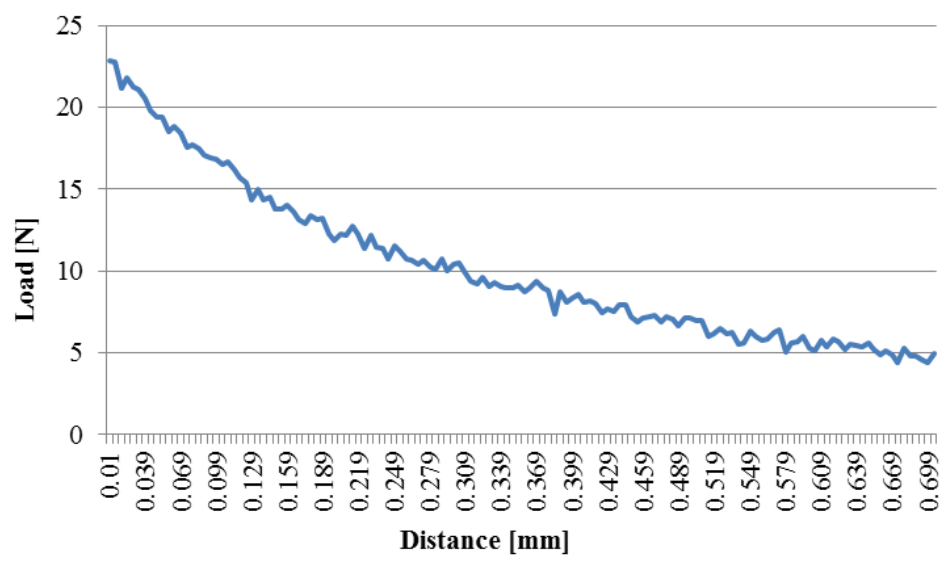

Fig. 10. Characteristics of change of the electromagnet attraction force as a function of the gap width and the intensity of the supplied current equal to $1.25 \mathrm{~A}$

The further minimal increase in current intensity to 1.25 A causes a decrease of electromagnet attraction force by approx. 50\%. Figures 11-14 show the characteristics of change of the electromagnet attraction force value depending on the current intensity value for different air gap distance values. 


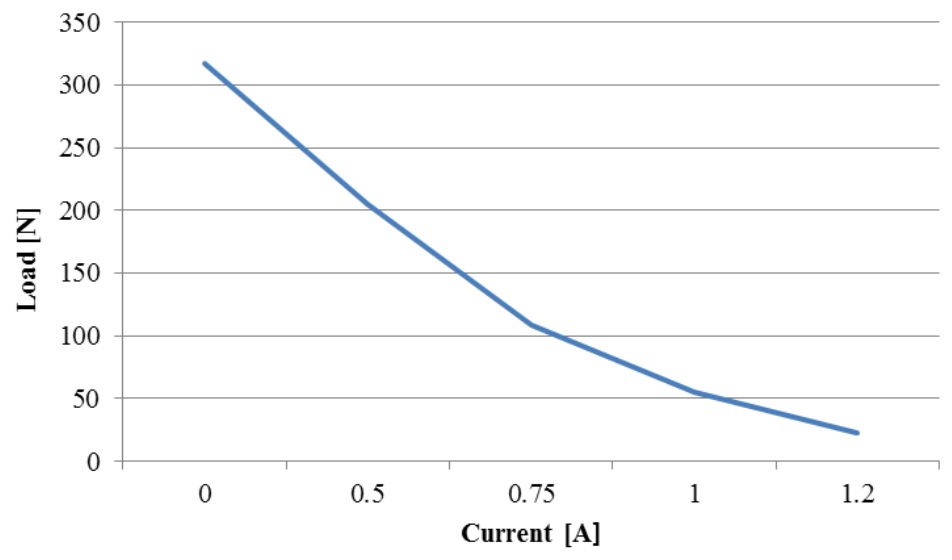

Fig. 11. Characteristics of change in the electromagnet attraction force as a function of current value in the coil for air gap distance equal to $0 \mathrm{~mm}$

The largest holding force value occurs at zero air gap width between the electromagnet and brake arm. The holding force of the electromagnet decreases as the current intensity increases.

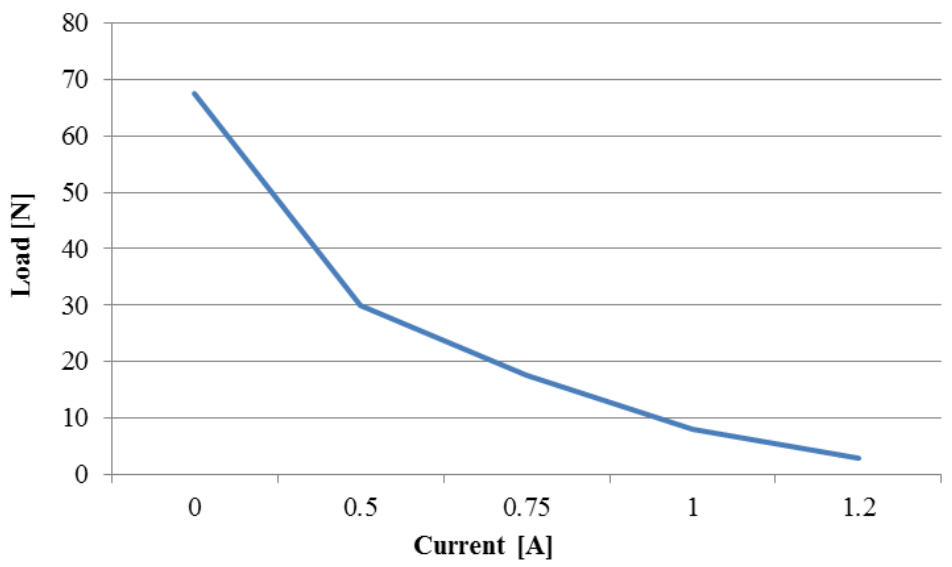

Fig. 12. Characteristics of change in the electromagnet attraction force as a function of current value in the coil for air gap distance equal to $1 \mathrm{~mm}$

Increasing the gap dimension by $1 \mathrm{~mm}$ causes a decrease in the holding force to $70 \mathrm{~N}$ at current value $0 \mathrm{~A}$. 


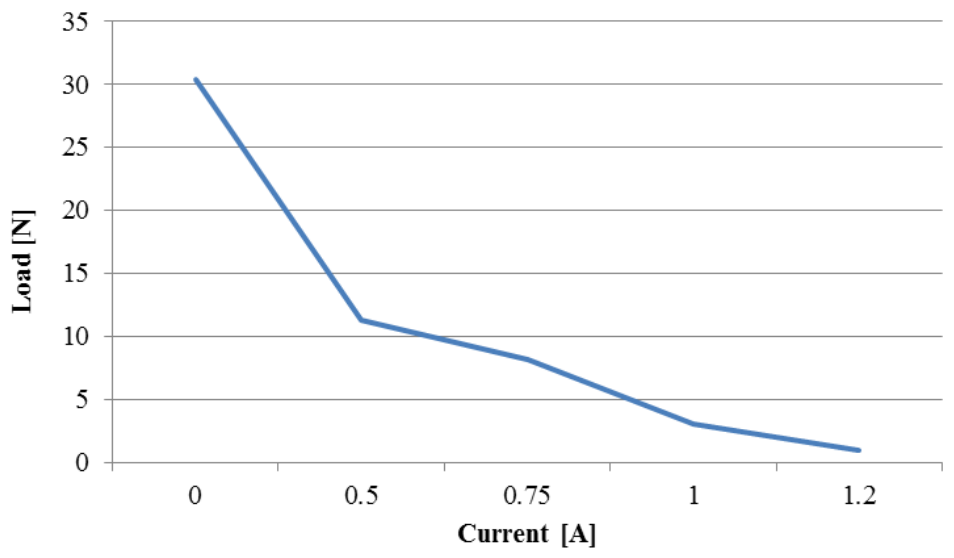

Fig. 13. Characteristics of change in the electromagnet attraction force as a function of current value in the coil for air gap distance equal to $2 \mathrm{~mm}$

The increase of the air gap dimension to $2 \mathrm{~mm}$ causes a decrease of the electromagnet holding force to $10 \%$ of its maximum value.

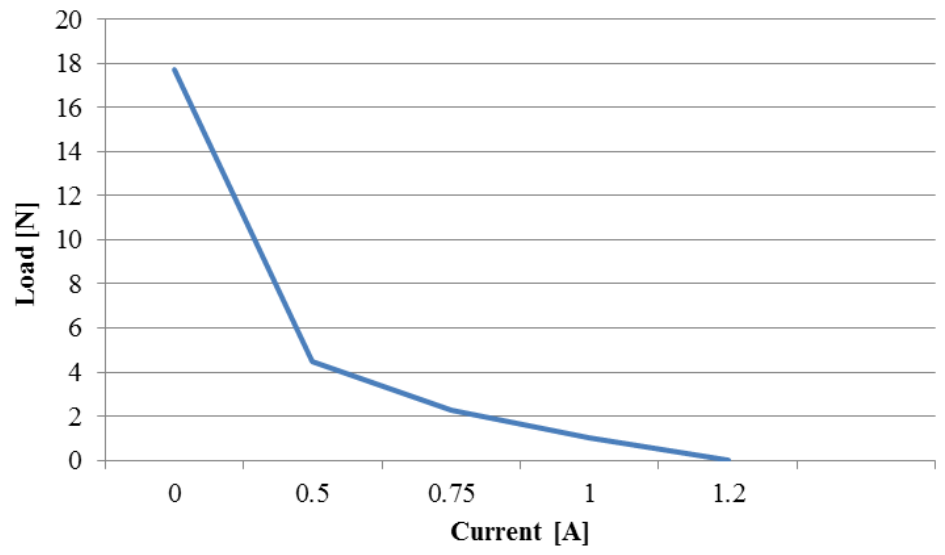

Fig. 14. Characteristics of change in the electromagnet attraction force as a function of current value in the coil for air gap distance equal to $3 \mathrm{~mm}$

The lowest system dynamics is achieved with air gap width of $3 \mathrm{~mm}$ (Fig. 7), because the attraction force of the brake arms by the electromagnet is the lowest.

The time constant described by the formula $\tau=L / R$ depends on inductance and resistance of the coil, which affects the current value in the electromagnet circuit and indirectly on the brake force on the actuator piston $[9,10]$. The electromagnet current intensity is described as follows:

$$
I=\frac{U}{R}\left(1-e^{-t \frac{R}{L}}\right)
$$


where: $U$ - supply voltage $[\mathrm{V}], R$ - coil resistance $[\Omega], L-$ coil inductance $[\mathrm{H}], t-$ time [sec].

The measurements were taken for coil resistance and inductance values of the electromagnet coil $R=3.6 \Omega, L=10.2 \mathrm{mH}$, and time constant was calculated $\tau=L / R=3 \mathrm{~ms}$.

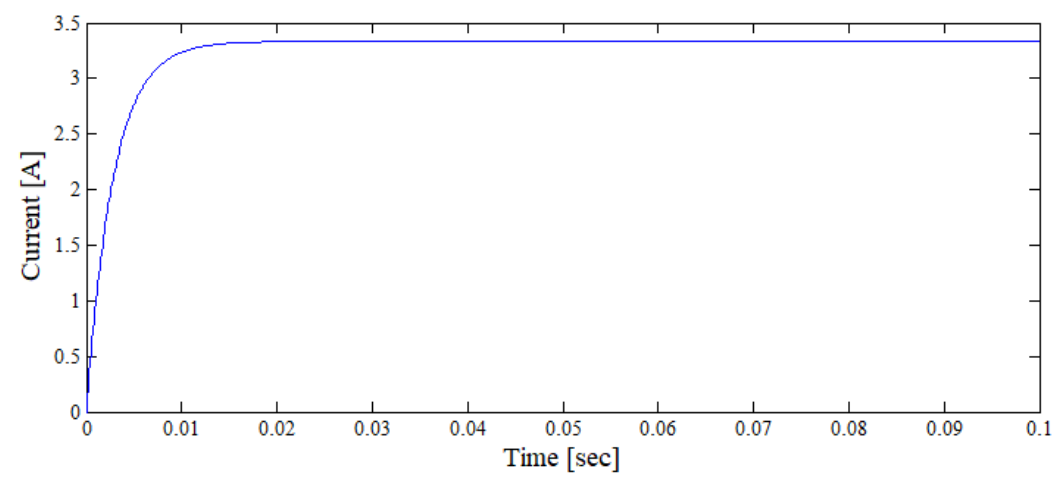

Fig. 15. Electromagnet current intensity as a function of time

The time constant associated with the electromagnet - brake arms system was measured. The measurement was performed with EVBavr 05 evaluation board with Atmega16 microprocessor and $8 \mathrm{MHz}$ timing frequency. The execution time for the time constant measuring program is $60 \mu \mathrm{s}$ which does not affect the accuracy of measurement. The reaction time for the control signal until the brake arms are attracted is $150 \mathrm{~ms}$. As seen on Figure 15, the time of increase of current intensity in the electromagnet coil and the execution of the program are negligibly small in comparison to the time constant of the mechanical system.

In order to decrease the time constant of the electromagnet - brake arms system, it is necessary to increase the rigidity of the beam which allows to reduce the dimension of the air gap to $0.4 \mathrm{~mm}$ (reduced beam deflection value). Based on the characteristics included in the drawings, one can notice its significant influence on the attraction force of the electromagnet. According to the formula $F=m \cdot a$, where $\mathrm{m}$ - brake arm mass, determines the dynamics of the system, and therefore the time constant of the positioning system. This allows to eliminate the non-linearity of the electromagnet's holding force depending on the air gap. Reduced time constant and the approximation of characteristics to linear range allow to control the attraction force of the electromagnet more accurately with the PID regulator, which affects positioning speed and accuracy. The increase of beam rigidity can be achieved by employing an T-beam or I-beam.

\section{Conclusions}

The most important advantages of the proposed solution for drive positioning are: low construction costs as well as higher accuracy and shorter positioning time. The presented positioning unit allows to maintain the set position and enables free programming the displacement of the actuator. Meeting such specified parameters is furthermore facilitated by a properly designed hybrid construction of the drive and control system. The study of the electromagnetic brake on the strength testing machine and measurement of time constants of the positioning system allowed to design an effective control system. 


\section{References}

1. R. Dindorf, J. Takosoglu, Inteligentne sterowanie serwonapędu pneumatycznego. Control Engineering, Nr 1(64), 50-58 (2010)

2. R. Dindorf, J. Takosoglu, Analiza serwonapędu pneumatycznego z regulatorami rozmytymi. Pneumatyka Nr 1, 51-53 (2005)

3. R. Dindorf, P. Łaski, J. Takosoglu, P. Woś, Pozycjonowanie serwonapędu elektropneumatycznego z bezpośrednim pomiarem przemieszczenia i prędkości tłoka sitownika. Acta Mechanica et Automatica, Vol. 4 No. 1, 86-91 (2010)

4. P. Perz, I. Malujda, D. Wilczyński, P. Tarkowski, Methods of controlling a hybrid positioning system using LabVIEW. Procedia Engineering, Vol. 177, 339-346 (2017)

5. P. Perz, D. Wilczyński, I. Malujda, Initial Research on the Positioning Performance of the Proposed Pneumatic Hybrid Drive. Machine Dynamics Research, Warsaw University of Technology, Vol. 38, No. 2, 95-100 (2014)

6. B. Kozak, Mechanika techniczna. WSiP, Warszawa 2004

7. J. Kortiš, L. Daniel, M. Handrik, The Numerical Analysis of the Joint of the Steel Beam to the Timber Girder. Procedia Engineering, Vol. 91, 160-164 (2014)

8. P. Kopas, L. Jakubovičová, M. Vaško, M. Handrik, Fatigue Resistance of Reinforcing Steel Bars. Procedia Engineering, Vol. 136, 193-197 (2016)

9. P. Perz, D. Wilczyński, I. Malujda, Pneumatic hybrid positioning system. Journal of Mechanical and Transport Engineering Publishing House of Poznan University of Technology, Vol. 66, No 2, 35-44 (2014)

10. J. Selech, D. Ulbrich, K. Włodarczyk, J. Kowalczyk, J. Adamkiewicz, The prototype of stream amplifier used in transport of polydisperse medium. Procedia Engineering, Vol. 192, 777-781, (2017), doi: 10.1016/j.proeng.2017.06.134 